\title{
LANDSCAPE-LEVEL THRESHOLDS AND NEWT CONSERVATION
}

\author{
Mathieu DenoëL ${ }^{1,3}$ and G. Francesco Ficetola ${ }^{2}$ \\ ${ }^{1}$ Laboratory of Fish and Amphibian Ethology, Behavioural Biology Unit, Department of Environmental Sciences, University of Liège, \\ 22 Quai van Beneden, 4020 Liège, Belgium \\ ${ }^{2}$ UMR CNRS 5553 Equipe génomique des populations et Biodiversité, University of Savoie, Le Bourget du Lac, France
}

\begin{abstract}
Ecological thresholds are defined as points or zones at which a rapid change occurs from one ecological condition to another. The existence of thresholds in species-habitat relationships has important implications for management, but the lack of concordance across studies and the wide range of methods used make generalizations difficult. We used two different statistical methods to test for the existence of thresholds for both individual species and the whole community, using three newt species as models. Based on a sample of 371 ponds, we found significant thresholds for both landscape configuration and composition. These were for the relationships between distance to forest and occurrence of Triturus alpestris and $T$. helveticus, and forest and crop cover and T. helveticus. Variability in the location of thresholds observed for the different species in this study caution against their use at the community level. Future studies should be based on the identification and assessment of thresholds for targeted species. Thresholds can be a useful concept from which tools may be developed to focus conservation effort for threatened species and their habitats.
\end{abstract}

Key words: breaking points; ecological thresholds; isolation; management goals; species richness; Triturus.

\section{INTRODUCTION}

The existence of ecological thresholds that indicate how or under what environmental conditions organisms may respond to change, and their usefulness in conservation, has been strongly debated over the past decade. Ecological thresholds are defined as points or zones at which a relatively rapid change occurs from one ecological condition to another (Huggett 2005, Luck 2005, Groffman et al. 2006). The existence of thresholds for the relationship between species and habitat has been proposed on the basis of theoretical studies and empirical evidence showing that the relationship between the amount of habitat loss and the degree of connectivity is nonlinear (With and Crist 1995, Keitt et al. 1997, Huggett 2005), and that extinction can happen abruptly when the habitat cover in a landscape falls below a given threshold (With and King 1999, Fahrig 2001, 2002).

If a threshold response exists, a minor change in the independent variable (e.g., habitat cover) can result in a dramatic change in the response variable, i.e., a decrease in the abundance or the disappearance of a species (With and King 1999, Fahrig 2001, Luck 2005). Therefore, ecological thresholds can be very important for landscape management (Groffman et al. 2006) as they can be viewed as "breaking points" in the species-habitat relationships. In identifying thresholds in the landscape, it is possible to propose appropriate management

Manuscript received 20 April 2006; accepted 5 May 2006. Corresponding Editor: R. A. Relyea.

${ }^{3}$ E-mail: Mathieu.Denoel@ulg.ac.be interventions, i.e., protection of parts of the landscape above critical thresholds to maintain species richness (Radford et al. 2005). Despite this, the use of thresholds in conservation planning has been criticized because there are technical issues associated with their identification and because evidence of their occurrence is controversial (Huggett 2005, Lindenmayer and Luck 2005). For example, empirical studies performed in different fragmented landscapes in Australia obtained variable results, sometimes with strong evidence of thresholds and sometimes with no evidence at all (reviewed by Huggett 2005). Large interspecific differences might explain discrepancies between studies and the absence of global thresholds (Lindenmayer et al. 2005, Lindenmayer and Luck 2005), but this hypothesis still deserves to be tested through studies focusing on variations in the expression of the threshold phenomenon for a range of different species.

Studies of thresholds for habitat suitability have evaluated mainly the effect of landscape composition (e.g., amount of habitat cover) on species' distribution in order to estimate the minimum amount of suitable habitat requiring preservation (Drinnan 2005, Guénette and Villard 2005, Radford et al. 2005). However, landscape configuration is another attribute that can play a pivotal role in the distribution of organisms (Fahrig 2002, Guerry and Hunter 2002). Landscape configuration includes attributes such as the distance among patches, and the spatial arrangement and shape of patches (Dunning et al. 1992, Gray et al. 2004). Among the attributes of landscape configuration, the distance between suitable patches could be particularly 
important for organisms that migrate between different elements of the landscape. For example, many amphibians breed in wetlands and spend the post-breeding season in upland environments. Similarly, several semiaquatic species of reptiles and mammals use upland and wetland environments for different, critical functions such as foraging or reproduction. For these species the distance between suitable habitats could be as critical as their extent; therefore the existence of thresholds for patch isolation could be extremely important for their management. However, with the exception of a few recent studies (Rodriguez and Andren 1999, van der Ree et al. 2003, Radford and Bennet 2004, Schultz and Crone 2005), isolation has been rarely studied in the analysis of thresholds.

A further problem in the analysis of thresholds is the wide range of methodologies used by different studies. The lack of a standardized methodology for the empirical detection of thresholds makes it difficult to compare the occurrence and characteristics of the phenomenon across studies. More rigorous statistical methods are therefore advocated to reduce the uncertainty with which thresholds are identified and used for conservation purposes (Huggett 2005). Because ecological thresholds are usually defined as zones of abrupt changes (Groffman et al. 2006), their detection requires methods that enable the detection of discontinuities in the relationships, and the test of the hypothesis that thresholds exist against more conventional hypotheses, such as linear relationships between habitat cover and species occurrence (e.g., Radford et al. 2005).

We studied the community of newts (genus Triturus) in an agricultural area of Belgium. Newts of genus Triturus breed in ponds and spent the post-breeding season in the terrestrial environment (Griffiths 1996), and the presence of forested areas has been demonstrated to be important for their survival (Joly et al. 2001, Schabetsberger et al. 2004, Van Buskirk 2005, Denoël and Lehmann 2006). In many areas of Europe, newts are declining because of several factors such as the introduction of alien species and ongoing landscape alteration (Collins and Storfer 2003, Beebee and Griffiths 2005, Denoël et al. 2005). In Belgium and most other European countries, all species are legally protected (see e.g., Beebee 1996: Bern Convention, Natura 2000 Directive, and local and national legislations). Legal recommendations to protect them are frequently limited to the interdiction of capture and habitat alteration (McLean et al. 1999), nevertheless actions for the improvement of habitat are ongoing in several European countries (e.g., Gentilli et al. 2003, Edgar et al. 2005). The small body size and limited dispersal ability of newts increase their susceptibility to habitat loss and fragmentation (Miaud 1990, Joly et al. 2001). Therefore newts are ideal candidates to explore the existence of ecological thresholds for habitat cover and isolation.
The aim of this study was to evaluate whether ecological thresholds exist in the relationships between landscape structure and newt distribution. The potential for threshold occurrence was determined for three different landscape attributes, encompassing both landscape composition and configuration: abundance of suitable terrestrial habitat (forest), distance between breeding areas and terrestrial habitat, and abundance of unsuitable terrestrial habitat (cover crops). Our study utilized recent statistical tools that allowed determinations of threshold position and significance.

\section{Methods \\ Study area}

We monitored 371 ponds between 1990 and 2004. Ponds were found on the basis of local topographic maps (Institut Géographique National, 1:20000 and 1:25000) to cover all the Pays de Herve. Ponds are relatively small $\left(457 \pm 71 \mathrm{~m}^{2}\right.$, mean $\left.\pm \mathrm{SE}\right)$. No large water bodies such as lakes are present in the study area. Pays de Herve is an agricultural area of eastern Belgium, which is mainly composed of meadows (primarily used by bovids), but it also contains deciduous and coniferous forest and cover crop (e.g., cereals) patches. The proportion of large homogeneous crop fields has been increasing during the last decades (Belayew et al. 1996, Denoël 2004). Pays de Herve sensu lato covers an area of $614 \mathrm{~km}^{2}$. It is limited by two major rivers (Meuse and Vesdre) and by national boundaries (The Netherlands and Germany).

To evaluate the presence of newts, each pond was both visually screened and sampled by performing several dozen dip-nettings, including blind ones (i.e., without previous visual detection of newts), during the active breeding period of newts (February-July; see Denoël 2004). Sampling effort was proportional to the complexity of habitats: the different micro-habitats were intensively prospected. We used cumulative occupancy such that a species was considered present when it was found at least once during the study period. Although we cannot reject the possibility of missing one species in a few cases, that would mean that the species was very rare in the studied pond. The habitat is thus probably not optimal and functions as a sink or a transient habitat (Perret et al. 2003). In this study, to reduce the probability to miss one species, we focused on the species that are not difficult to find (T. alpestris, $T$. helveticus, and T. vulgaris). Thus, T. cristatus, which is slightly more secretive and present in only 12 ponds (Denoël 2004), was not included in the analysis.

\section{Landscape traits}

For each pond, we measured, using topographical maps, the percentage of forest and crop cover within a radius of $400 \mathrm{~m}$ (i.e., $50 \mathrm{ha}$ ), and the straight-line distance from the nearest forest. The radius of $400 \mathrm{~m}$ encompasses the average migration distance of newts and salamanders (Miaud 1990, Semlitsch 1998, Scha- 
betsberger et al. 2004, Smith and Green 2005), and it is used in several other studies on distribution patterns (see Joly et al. 2001 for application in Triturus newts). It allows consideration of a wide range of landscape compositions that are typical of the study area (Denoël 2004). The correlation between forest and crop cover was significant but quite weak (Pearson's $r=-0.155, n=$ $371, P<0.01)$; therefore the effect of crop cannot be explained as a mere effect of collinearity with the amount of suitable habitat (i.e., forest). Distance to forest and forest cover are inherently correlated, therefore we evaluated if the observation of thresholds in response to both these features reflects their independent effect or is caused by mere collinearity (see Results).

\section{Statistical analyses}

To analyze the presence of threshold effect in the relationships between landscape configuration (distance to forest) and newt distribution, we calculated the proportion of ponds occupied by newts and the average number of species per pond, at 10 distance intervals from forest: $0-50 ; 51-100 ; 101-200 ; 201-300 ; 301-400$; 401-500; 501-600; 601-800; 801-1000; and $>1000 \mathrm{~m}$. The intervals were unequal to account for the decreasing frequency of ponds at increasing distance from the forest and were used in the analyses as a rank scale. Similarly, to evaluate the presence of thresholds in the relationship between landscape composition (percent forest cover) and newt distribution, we divided the forest percent cover in 10\% intervals (deciles) and we calculated the proportion of ponds occupied in each decile (Homan et al. 2004). Similarly, we divided the crop percent cover in $5 \%$ intervals, and we calculated the proportion of ponds occupied per each 5\% interval, because the maximum crop percentage surrounding a pond was $47 \%$.

We analyzed the presence of thresholds in the relationships between newt distribution (proportion of occupied ponds for each species) and landscape features by using two statistical approaches. We evaluated the presence of structural changes (breakpoints) in the relationships suggesting that a change in state occurs around a specific point (Zeileis et al. 2003). Moreover, we also used piecewise regression (Toms and Lesperance 2003, Homan et al. 2004).

First, we used the model developed by Zeileis et al. $(2002,2003)$ to estimate the number and position of unknown breakpoints. This method computed an $F$ statistic (Andrews 1993) for every potential breaking point, then the $\sup F$ statistic was used to test their significance. This method was originally developed for the analyses of time series, but can be applied to any ordered series. It has been shown to be capable of detecting changes in the mean of series as well as in the coefficients of regressions that coincide with wellidentified events that might have caused the break (Zeileis et al. 2003). We also evaluated the possibility of multiple breakpoints, but we never found more than a single significant potential breakpoint.

Second, the potential presence of thresholds was also analyzed using the piecewise regression (Muggeo 2003, 2004, Toms and Lesperance 2003, Homan et al. 2004). We built piecewise linear regression models, with a breakpoint in the position estimated by using the Zeileis's (2003) method. The significance of breakpoints in piecewise regressions was evaluated by determining if these regression models performed significantly better than simple linear regression models.

Breakpoint analyses were performed using the package strucchange 1.2 (Zeileis et al. 2002, 2005); piecewise linear regressions were fitted using segmented 0.1 (Muggeo 2003, 2004). All analyses were performed under R 2.2 (R Development Core Team 2005).

\section{Removing pond features as potentially confounding factors}

Our study focused on the presence of thresholds at landscape levels. However, pond features can be extremely important for newts and can be related to landscape features. Pond features having major effects on amphibian communities are fish presence and canopy cover (Skelly et al. 1999, 2002, Joly et al. 2001, Ficetola and De Bernardi 2004, Denoël and Lehmann 2006). To evaluate if the negative effects of fish on newts affect the results of the analysis of thresholds, we repeated the analysis after removing the 49 ponds where fish are known to be present (M. Denoël and G. F. Ficetola, unpublished data).

We did not measure directly canopy cover on the field, but we can assume that ponds within the forest have larger canopy cover than those outside the forest. To evaluate if canopy cover influences the distribution of newts, and therefore if it could affect our results, we compared newt occupancy in ponds within the forest $(n=104)$ with ponds close but outside to the forest $(10 \mathrm{~m} \leq$ distance $<50 \mathrm{~m}, n=25)$.

\section{RESUlts}

Triturus alpestris and $T$. vulgaris were the most common species. Both species were found in $25.5 \%$ of ponds. T. helveticus was observed in $9.0 \%$ of ponds. The mean number of species per pond $( \pm \mathrm{SE})$ was $0.63 \pm$ 0.046 .

Overall, we obtained similar results by using the two statistical methods to evaluate the significance of potential thresholds (Table 1). In two cases, the Zeileis et al. (2003) method detected the presence of a significant threshold that was not significant using the piecewise regression.

We observed a significant threshold effect of distance from the forest for T. alpestris and T. helveticus (Table 1, Fig. 1A, B). The presence of $T$. alpestris declined with the distance from the forest in ponds that are up to 400 $\mathrm{m}$ away from the forest. After this distance, the species was rare and the occurrence did not decline anymore. 
TABLE 1. Ecological thresholds in newt species using two statistical methods.

\begin{tabular}{|c|c|c|c|c|}
\hline \multirow[b]{3}{*}{ Occurrence, species } & \multicolumn{2}{|c|}{ Breaking point } & \multirow{2}{*}{\multicolumn{2}{|c|}{ Piecewise regression }} \\
\hline & \multirow{2}{*}{$\begin{array}{c}\sup F \\
(n=10) \dagger\end{array}$} & \multirow[b]{2}{*}{$P$} & & \\
\hline & & & $F_{7,1}$ & $P$ \\
\hline \multicolumn{5}{|l|}{ Distance to forest } \\
\hline T. alpestris & 11.222 & 0.034 & 5.332 & 0.054 \\
\hline T. helveticus & 82.274 & $<0.0001$ & 23.403 & 0.002 \\
\hline T. vulgaris & 5.874 & 0.280 & 0.959 & 0.360 \\
\hline \multicolumn{5}{|l|}{ Forest percentage } \\
\hline T. alpestris & 8.765 & 0.092 & 0.140 & 0.719 \\
\hline T. helveticus & 29.603 & $<0.0001$ & 8.639 & 0.022 \\
\hline T. vulgaris & 12.642 & 0.018 & 0.148 & 0.712 \\
\hline \multicolumn{5}{|l|}{ Crop percentage } \\
\hline T. alpestris & 1.367 & 0.983 & 1.363 & 0.281 \\
\hline T. helveticus & 29.120 & $<0.0001$ & 33.549 & 0.0007 \\
\hline T. vulgaris & 1.276 & 0.990 & 0.007 & 0.934 \\
\hline
\end{tabular}

$\dagger$ Chow test statistic, see Andrews (1993), Zeileis et al. (2003); $n$, number of intervals into which distance to forest, forest, and crop percentages were divided.

Similarly, the occurrence of $T$. helveticus declined with distance from forest, but this species was almost completely absent from all the ponds that are $>200 \mathrm{~m}$ far from the forest. We did not find a significant breakpoint for T. vulgaris (Table 1). For T. helveticus, we observed a significant threshold effect of forest cover within $400 \mathrm{~m}$ : the occurrence of this species increased with forest cover up to $40 \%$ of cover, but was constant above this value (Table 1, Fig. 1F). Using the Zeileis et al. (2003) method, we observed a significant threshold effect of forest cover also for $T$. vulgaris, but this threshold was not significant using the piecewise regression (Table 1). The occurrence of $T$. vulgaris decreased with increasing forest cover from $20 \%$ to $70 \%$ (Fig. 1G). We did not find a significant breakpoint in the relationship between forest percentage and the presence of T. alpestris (Table 1).

For crop percentage, we did not find significant thresholds for $T$. alpestris and T. vulgaris, while we found a significant threshold for T. helveticus (Table 1, Fig. 1J). We never observed $T$. helveticus in ponds having $>15 \%$ of crop cover within $400 \mathrm{~m}$. However, it should be noted that the power of this latter analysis was probably low because (1) none of the ponds was surrounded by $>50 \%$ of crop; therefore none of the ponds was surrounded by landscape strongly unfavorable because of the exploitation by agriculture, and (2) only 15 ponds were surrounded by $>25 \%$ of crops; therefore the mean occupancy values associated with the categories having cover $>25 \%$ were based on a very small sample, as showed also by the wide associated standard errors (Fig. 1I-L).

The analysis performed on the subset of fishless ponds $(n=322)$ provided virtually identical results (Appendix). Both methods always detected significant thresholds if a threshold was detected by using the complete data set. The Zeileis et al. (2003) method also detected a threshold in the relationship between occurrence of $T$. alpestris and forest percentage, with an abrupt increase in species occurrence when forest cover rises above $70 \%(P=$ 0.008 , see Fig. 1). However, the sample size of the $60 /$ $70 \%$ and $70 / 80 \%$ deciles was very small (both $n=2$ ) and the piecewise regression did not detect this threshold $(P=0.573)$.

In ponds close to the forest edge, newt occupancy within and outside the forest was not significantly different (likelihood ratio test; T. alpestris, $\chi_{1}^{2}=0.036$, $P=0.850 ; T$. vulgaris, $\chi_{1}^{2}=1.324, P=0.250 ; T$. helveticus, $\left.\chi_{1}^{2}=2.249, P=0.134\right)$. This suggests that differences in canopy cover do not bias our results.

Both forest cover and distance to forest had a significant threshold effect on Triturus helveticus (Table 1). To evaluate if these features had independent effects, we compared occupancy among ponds having distance to the forest lower than the threshold value (distance $\leq$ $150 \mathrm{~m})$ but different forest cover. Similarly, we compared occupancy among ponds having forest cover lower than the threshold value (cover $\leq 30 \%$ ) but with different distance to forest. None of the ponds in the study area had both forest cover $>30 \%$ and distance to forest $>150 \mathrm{~m}$. In ponds close to the forest, the occupancy of $T$. helveticus was much higher if forest cover was $>30 \%$ (occupancy, $\mathrm{O}=34 \%$ ) than if it was $\leq 30 \%(\mathrm{O}=4.3 \%)$. This means an independent effect of forest cover, keeping equal distance to forest. Likewise, in ponds surrounded by low forest percentage, the occupancy was higher if the distance to forest was $\leq 150 \mathrm{~m}(\mathrm{O}=4.3 \%)$ than if it was $>150 \mathrm{~m}(\mathrm{O}=1.3 \%)$. This means an independent effect of distance to forest, keeping equal forest cover.

\section{DisCUSSION}

We found evidence of the existence of thresholds in the relationship between newt distribution and landscape features. The presence of thresholds was particularly clear and significant for one species (T. helveticus), 

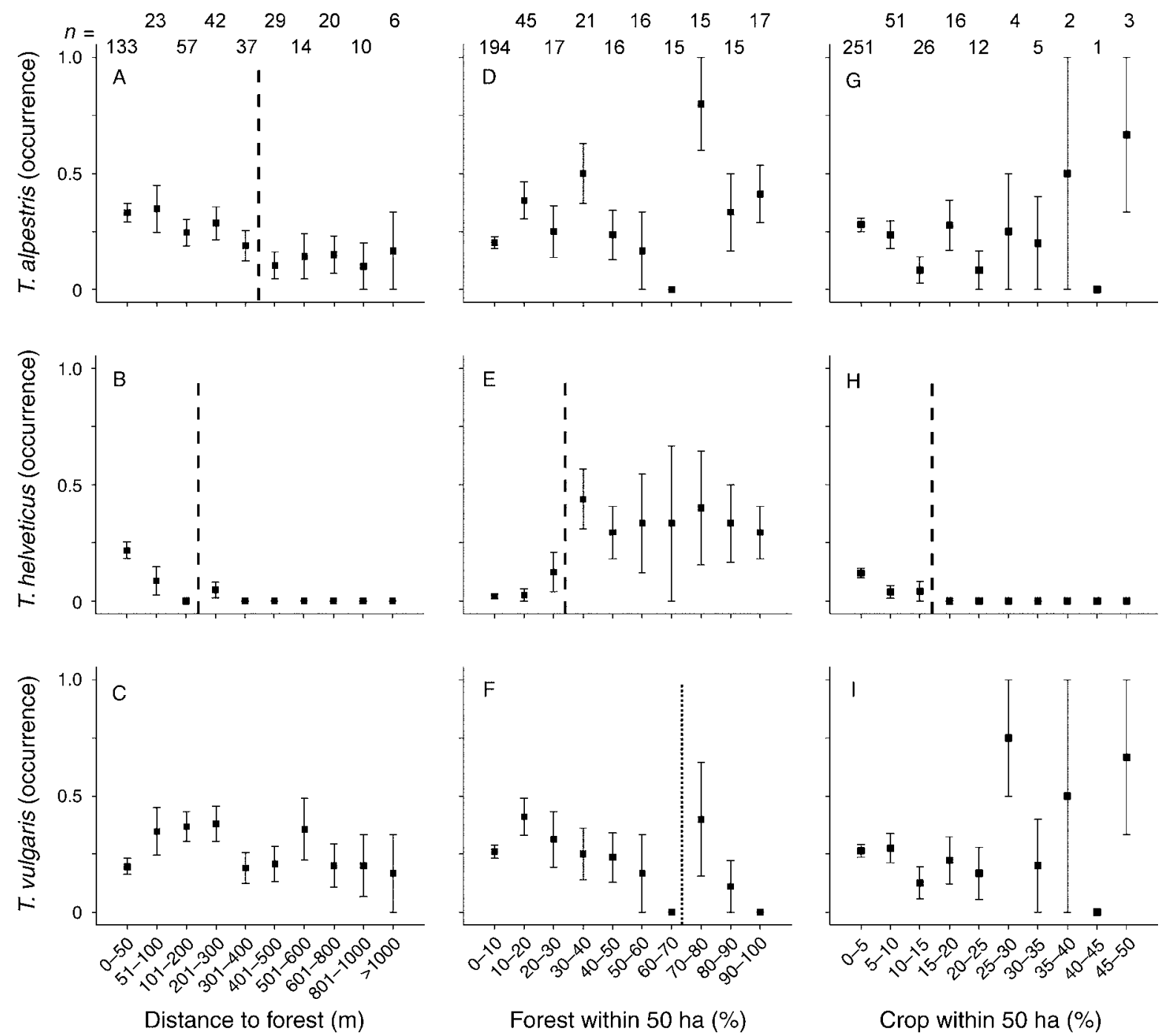

FIG. 1. Occurrence of three newt species in 371 ponds (mean $\pm \mathrm{SE}$ ), at different distances from the nearest forest and in different forest/crop cover within a $400 \mathrm{~m}$ radius. Thick dashed lines represent significant breakpoints following both the Zeileis et al. (2003) method and the piecewise regression; thin dotted lines represent significant breakpoints following only the Zeileis et al. (2003) method; sample sizes are provided in the upper graphs; $n$ is the number of ponds.

but thresholds were detected also for the other species (T. alpestris and T. vulgaris). The relationship between newt distribution and isolation of wetlands from the terrestrial habitat showed a clear threshold pattern for two out of three analyzed species. This suggests that there can be a significant threshold pattern for landscape configuration, and that the existence of these thresholds should be taken into consideration in the planning and management of landscapes (see also Radford and Bennet 2004). Although other studies have attributed the absence of significant thresholds to the use of a binary variable (Guerry and Hunter 2002), our study shows that such a response variable can be reliable to detect thresholds. The two different methods used for the analysis produced similar results, suggesting that the observed thresholds correspond to real breaking points in the species-habitat relationships. Only in one case (the relationship between $T$. vulgaris and forest cover) was a threshold significant using only the Zeileis et al. (2003) method, suggesting caution on the interpretation of this result. Further studies are required to evaluate which technique generates the most reliable results under different types of landscapes. Both methods are freeware packages implemented in the same statistical environment. Until now, the use of a wide range of analytical methods partially hampered the possibility of comparisons across studies (Huggett 2005, Lindenmayer and Luck 2005). The free availability of the statistical tools and the existence of a wide online documentation could allow them to be more universally used and make comparisons between studies possible. 
Landscape configuration, i.e., the distance to the nearest forest, is an important variable for two of the studied species, mainly $T$. helveticus, but also $T$. alpestris. Triturus newts usually move from land to wetlands each year after the winter period and backward after breeding (von Lindeiner 1992, Griffiths 1996). These newts are small in size, are not very mobile, and rely on external cues to locate habitat suitable for reproduction (Joly and Miaud 1993, Malmgrem 2001). Because of their need for suitable aquatic and terrestrial habitats, habitat complementation (i.e., the need of different habitats throughout the life cycle; Dunning et al. 1992) is particularly important for them (Joly et al. 2001). Ponds must therefore not be isolated from forests for some of the study species. For example, T. helveticus is a forest species that can use habitats in open areas such as meadows, but these need to be situated close to forest edges. The detection of a threshold value indicates that the breeding ponds have to be within a given distance from the terrestrial habitat, and provides a quantitative estimate of the maximum distance between forest and ponds suitable for breeding. Management actions to improve the suitability of wetlands for these species or to create new breeding habitat (e.g., Edgar et al. 2005) should focus on ponds that are within the observed threshold distance from the forest (see also Guénette and Villard 2005). The fact that newts are similarly present in ponds within forest patches, i.e., under high canopy cover, and close to forest edge but in more open and sunny areas, indicates that forest is primarily important as terrestrial habitat. This is in contrast with other amphibians. For example, several species belonging to the genera Bufo, Hyla, Notophthalmus, Pseudacris, and Rana, are thermophile and prefer more sunny areas, which are different in features including light, temperature, food availability, and dissolved oxygen (Werner and Glennemeier 1999, Skelly et al. 1999, 2002, Halverson et al. 2003, Ficetola and De Bernardi 2005).

Landscape composition is another important factor for amphibian ecological requirements (Guerry and Hunter 2002, Homan et al. 2004, Van Buskirk 2005). In this study, we found thresholds for the percentage of both forest and crop cover. The weak correlation between these attributes suggests that $T$. helveticus shows a response to the global quality of terrestrial habitat, and requires not only that a given amount of suitable habitat is present, but also that the amount of unsuitable habitat is less than a specific level. Again, the detected threshold values can inform the conservation management of populations. However, it is important not to confuse occupancy with viability (Radford et al. 2005). The thresholds we observed are the thresholds for occupancy of ponds, but newts can be present in ponds that are surrounded by a partially unsuitable landscape, in populations with negative demographic trends, and/ or in sink populations within metapopulations. Moreover, thresholds are points of rapid change of the relationships and of instability. Therefore, following the precautionary principle, the management goal should be to preserve landscapes well above the critical threshold value (Radford et al. 2005).

For the other species, the variability in the amount of suitable habitats in Pays de Herve does not seem to cause abrupt effects on populations. In areas where large crop fields are now the dominant type of agricultural land use, some species of newts can suffer substantially from these activities (see e.g., Joly et al. 2001). However, not all the species show the same pattern. For example, $T$. vulgaris tended to be more frequent in areas with many crop fields but, in this case, no significant thresholds were detected. Our study demonstrates that different species can show different responses to landscape alteration, and that threshold relationships can be present only for some species even in the same community, despite the use of the same analytical methods. Individual species have peculiarities that preclude generalizations, and threshold patterns can be present only for a subsample of the species in a landscape (Lindenmayer et al. 2005, Lindenmayer and Luck 2005, Radford et al. 2005).

The position of thresholds was highly variable across species and this is consistent with simulation studies (Keitt et al. 1997, With and King 1999, Fahrig 2001). For example, the presence of $T$. alpestris declined with distance from the forest until a distance of $400 \mathrm{~m}$, suggesting that $400 \mathrm{~m}$ is a threshold for maximum isolation between forest and wetlands for this species. We found a similar pattern for $T$. helveticus, but the threshold was located at a distance of $\sim 200 \mathrm{~m}$. Triturus alpestris has a larger body size than $T$. helveticus, and larger species of newts tend to have greater dispersal distances (reviewed by Smith and Green 2005); therefore the differences in the position of the thresholds could be partly caused by interspecific differences in dispersal ability.

Conservation plans often rely on the protection of one or several "umbrella species," assuming that their requirement of large habitat amounts ensure the protection for the whole community. The process of selection of umbrella species should include the identification of the species with the most demanding requirements (Lambeck 1997). The analysis of thresholds can be helpful to this complex task, because the comparison among species can identify those showing the most sensitive threshold values; in turn, these values can provide practical targets for the landscape management (Hugget 2005). For instance, umbrella species are frequently large and showy organisms; in $89 \%$ of studies reviewed by Roberge and Angelstam (2004), candidate umbrella species were selected among large mammals or birds. However, the small, terrestrial species can be particularly sensitive to loss of connectivity and changes in landscape configuration. Our study shows that in systems dealing with issues of connectivity it can be 
necessary to focus on the requirements of the smallest members of the community, such as $T$. helveticus.

Even within homogeneous species groups or guilds, interspecific differences for habitat requirements (Joly et al. 2001, Guerry and Hunter 2002, Van Buskirk 2005) and dispersal ability (Semlitsch 1998, Smith and Green 2005) emphasize the importance of studies targeted at the individual species requiring management intervention. This was clearly shown in our threshold analysis with the three species largely differing in their response to the studied variables. Effective conservation measures should focus on each species individually, particularly when some are threatened with extinction (see also Guerry and Hunter 2002). The results also support recent studies that argue for the importance of uplands in the conservation of pond-breeding amphibians (Semlitsch 1998, Pope et al. 2000, Guerry and Hunter 2002, Houlahan and Findlay 2003, Schabetsberger et al. 2004, Herrmann et al. 2005). The threshold method can be a valuable tool to identify priority conservation areas. As funding is usually limited and allows the protection of only a part of the populations, targeting the efforts on the areas defined by the threshold method would help to protect the species efficiently. When funding is limited, management should be focused first on the areas satisfying the requirements of the species having the shortest thresholds. This could allow to protect the populations also for other species having less restrictive threshold values. This is particularly important in agricultural areas in which forests consist of isolated patches and in which the land is becoming increasingly used for crop fields. In a perspective of better funding, these core populations could function as sources of colonizing individuals toward more peripheral habitats that can be later protected. Thresholds are thus an efficient tool for managers to solve basic problems such as the efficiency of funding use.

\section{ACKNOWLEDGMENTS}

We are grateful to M. Brambilla, R. N. Homan, M. Hunter, A. Huggett, A. Smith, A. Zeileis, and an anonymous reviewer for their constructive comments on the manuscript, to L. Dumont, F. Hourlay, and P. Petitfrère for field help. We also thank the Ministère de la Region Wallonne for funding and authorizing this study. M. Denoël is Research Associate at the Fonds National de la Recherche Scientifique (FNRS, Belgium); G. F. Ficetola is a post-doc funded by a grant of the French Ministry for Research for young foreign researchers.

\section{Literature Cited}

Andrews, D. W. K. 1993. Tests for parameter instability and structural change with unknown change point. Econometrica 61:821-856.

Beebee, T. 1996. Ecology and conservation of amphibians. Chapman and Hall, London, UK.

Beebee, T. J. C., and R. A. Griffiths. 2005. The amphibian decline crisis: a watershed for conservation biology? Biological Conservation 125:271-285.

Belayew, D., A. Froment, C. Hallet, F. Orban-Ferauge, and C. Van der Kaa. 1996. Etat de l'environnement wallon: Paysage. Ministère de la Région Wallonne, Jambes, Belgium.
Collins, J. P., and A. Storfer. 2003. Global amphibian declines: sorting the hypotheses. Diversity and Distribution 9:89-98.

Denoël, M. 2004. Répartition, habitat et conservation des amphibiens du Pays de Herve (Belgique). Bulletin de la Société Herpétologique de France 111-112:49-77.

Denoël, M., G. Dzukic, and M. Kalezic. 2005. Effect of widespread fish introductions on paedomorphic newts in Europe. Conservation Biology 19:162-170.

Denoël, M., and A. Lehmann. 2006. Multi-scale effect of landscape processes and habitat quality on newt abundance: implications for conservation. Biological Conservation 130: 495-504.

Drinnan, I. N. 2005. The search for fragmentation thresholds in a southern Sydney suburb. Biological Conservation 124:339349.

Dunning, J. B., B. J. Danielson, and H. R. Pulliam. 1992. Ecological processes that affect populations in complex landscapes. Oikos 65:169-175.

Edgar, P. W., R. A. Griffiths, and J. P. Foster. 2005. Evaluation of translocation as a tool for mitigating development threats to great crested newts. Biological Conservation 122:45-52.

Fahrig, L. 2001. How much habitat is enough? Biological Conservation 100:65-74.

Fahrig, L. 2002. Effect of habitat fragmentation on the extinction threshold: a synthesis. Ecological Applications 12:346-353.

Ficetola, G. F., and F. De Bernardi. 2004. Amphibians in a human-dominated landscape: the community structure is related to habitat features and isolation. Biological Conservation 119:219-230.

Ficetola, G. F., and F. De Bernardi. 2005. Influence of hydroperiod, sun exposure and fish presence on amphibian communities in a human dominated landscape. Pages 140 142 in N. Ananjeva and O. Tsinenko, editors. Herpetologia Petropolitana, St. Petersburg, Russia.

Gentilli, A., S. Scali, F. Barbieri, and F. Bernini. 2003. A three year project for the management and the conservation of amphibians in Northern Italy. Pages 27-33 in M. Vogrin, editor. Proceedings of the 11th Ordinary General Meeting Societas Europaea Herpetologica. Biota. Zalec, Slovenia.

Gray, M. J., L. M. Smith, and R. I. Leyva. 2004. Influence of agricultural landscape structure on a Southern High Plains, USA, amphibian assemblage. Landscape Ecology 19:719729.

Griffiths, R. A. 1996. Newts and salamanders of Europe. T. and A. D. Poyser Natural History, London, UK.

Groffman, P. M., et al. 2006. Ecological thresholds: the key to successful environmental management or an important concept with no practical application? Ecosystems 9:1-13.

Guénette, J.-S., and M.-A. Villard. 2005. Thresholds in forest bird response to habitat alteration as quantitative targets for conservation. Conservation Biology 19:1168-1180.

Guerry, A. D., and M. L. J. Hunter. 2002. Amphibian distributions in a landscape of forests and agriculture: an examination of landscape composition and configuration. Conservation Biology 16:745-754.

Halverson, M. A., D. K. Skelly, J. M. Kiesecker, and L. K. Freidenburg. 2003. Forest mediated light regime linked to amphibian distribution and performance. Oecologia 134: 360-364.

Herrmann, H. L., K. J. Babbitt, M. J. Baber, and R. G. Congalton. 2005. Effects of landscape characteristics on amphibian distribution in a forest-dominated landscape. Biological Conservation 123:139-149.

Homan, R. N., B. S. Windmiller, and J. M. Reed. 2004. Critical thresholds associated with habitat loss for two vernal pondbreeding amphibians. Ecological Applications 14:1547-1553.

Houlahan, J. E., and C. S. Findlay. 2003. The effects of adjacent land use on wetland amphibian species richness and 
community composition. Canadian Journal of Fisheries and Aquatic Sciences 60:1078-1094.

Huggett, A. J. 2005. The concept and utility of "ecological thresholds" in biodiversity conservation. Biological Conservation 124:301-310.

Joly, P., and C. Miaud. 1993. How does a newt find its pond? The role of chemical cues in migrating newts (Triturus alpestris). Ethology Ecology and Evolution 5:447-455.

Joly, P., C. Miaud, A. Lehmann, and O. Grolet. 2001. Habitat matrix effects on pond occupancy in newts. Conservation Biology 15:239-248.

Keitt, T. H., D. L. Urban, and B. T. Milne. 1997. Detecting critical scales in fragmented landscapes. Conservation Ecology 1(1):4. 〈www.consecol.org/voll/iss1/art4〉

Lambeck, R. J. 1997. Focal species: a multi-species umbrella for nature conservation. Conservation Biology 11:849-856.

Lindenmayer, D. B., J. Fischer, and R. B. Cunningham. 2005. Native vegetation cover thresholds associated with species responses. Biological Conservation 124:311-316.

Lindenmayer, D. B., and G. W. Luck. 2005. Synthesis: thresholds in conservation and management. Biological Conservation 124:351-354.

Luck, G. W. 2005. An introduction to ecological thresholds. Biological Conservation 124:299-300.

Malmgrem, J. C. 2001. Evolutionary ecology of newts. Published Ph.D. thesis. Örebro University, Örebro, Sweden.

McLean, I. F. G., A. D. Wight, and G. Williams. 1999. The role of legislation in conserving Europe's threatened species. Conservation Biology 13:966-969.

Miaud, C. 1990. La dynamique des populations subdivisées: étude comparative chez trois amphibiens urodèles (Triturus alpestris, T. helveticus et T. cristatus). Ph.D. thesis. Claude Bernard Lyon I Universiy, Villeurbanne, France.

Muggeo, V. M. R. 2003. Estimating regression models with unknown break-points. Statistics in Medicine 22:3055-3071.

Muggeo, V. M. R. 2004. Segmented: segmented relationships in regression models. R package version 0.1-4. 〈www.r-project. org $\rangle$

Perret, N., R. Pradel, C. Miaud, O. Grolet, and P. Joly. 2003. Transience, dispersal and survival rates in newt patchy populations. Journal of Animal Ecology 72:567-575.

Pope, S. E., L. Fahrig, and H. G. Merriam. 2000. Landscape complementation and metapopulation effects on leopard frog populations. Ecology 81:2498-2508.

Radford, J. Q., and A. F. Bennet. 2004. Thresholds in landscape parameters: occurrence of the white-browed treecreeper Climacteris affinis in Victoria, Australia. Biological Conservation 117:375-391.

Radford, J. Q., A. F. Bennet, and G. J. Cheers. 2005. Landscape-level thresholds of habitat cover for woodlanddependent birds. Biological Conservation 124:317-337.

R Development Core Team. 2005. R: a language and environment for statistical computing. R Foundation for Statistical Computing, Vienna, Austria.

Roberge, J.-M., and P. Angelstam. 2004. Usefulness of the umbrella species concept as a conservation tool. Conservation Biology 18:76-85.
Rodriguez, A., and H. Andren. 1999. A comparison of Eurasian red squirrel distribution in different fragmented landscapes. Journal of Applied Ecology 36:649-662.

Schabetsberger, R., R. Jehle, A. Maletzky, J. Pesta, and M. Sztatecsny. 2004. Delineation of terrestrial reserves for amphibians: post-breeding migrations of Italian crested newts (Triturus c. carnifex) at high altitude. Biological Conservation 117:95-104.

Schultz, C. B., and E. E. Crone. 2005. Patch size and connectivity thresholds for butterfly habitat restoration. Conservation Biology 19:887-896.

Semlitsch, R. D. 1998. Biological delineation of terrestrial buffer zones for pond-breeding salamanders. Conservation Biology 12:1113-1119.

Skelly, D. K., L. K. Freidenburg, and J. M. Kiesecker. 2002. Forest canopy and the performance of larval amphibians. Ecology 83:983-992.

Skelly, D. K., E. E. Werbner, and S. A. Cortwright. 1999. Long-term distribution dynamics of a Michigan amphibian assemblage. Ecology 80:2326-2337.

Smith, M. A., and D. M. Green. 2005. Dispersal and the metapopulation paradigm in amphibian ecology and conservation: are all amphibian populations metapopulations? Ecography 28:110-128.

Toms, J. D., and M. L. Lesperance. 2003. Piecewise regression: a tool for identifying ecological thresholds. Ecology 84:20342041.

Van Buskirk, J. 2005. Local and landscape influence on amphibian occurrence and abundance. Ecology 86:1936 1947.

van der Ree, R., A. F. Bennett, and D. C. Gilmore. 2003. Gapcrossing by gliding marsupials: thresholds for use of isolated woodland patches in an agricultural landscape. Biological Conservation 115:241-249.

von Lindeiner, A. 1992. Untersuchungen zur Populationsökologie von Berg-, Faden- und Teichmolch (Triturus alpestris L., T. helveticus Razoumowski, T. vulgaris L.) an ausgewählten Gewässern im Naturpark Schönbuch (Tübingen). Jahrbuch für Feldherpetologie 3:1-117.

Werner, E. E., and K. S. Glennemeier. 1999. Influence of forest canopy cover on the breeding pond distributions of several amphibian species. Copeia 1999:1-12.

With, K. A., and T. O. Crist. 1995. Critical thresholds in species' responses to landscape structure. Ecology 76:2446-2459.

With, K. A., and A. W. King. 1999. Extinction threshold for species in fractal landscapes. Conservation Biology 13:314 326.

Zeileis, A., C. Kleiber, W. Krämer, and K. Hornik. 2003. Testing and dating of structural changes in practice. Computational Statistics and Data Analysis 44:109-123.

Zeileis, A., F. Leisch, B. Hansen, K. Hornik, C. Kleiber, and A. Peters. 2005. The strucchange package: testing for structural change. 〈www.R-project.org〉

Zeileis, A., F. Leisch, K. Hornik, and C. Kleiber. 2002. Strucchange: an R package for testing for structural change in linear regression models. Journal of Statistical Software 7: $1-38$.

\section{APPENDIX}

A table showing significance of ecological thresholds in newt species, evaluated after removing from the data set ponds with fish (Ecological Archives A017-012-A1). 